\title{
A contribuição da instrução e do treinamento fonético no ensino de L2
}

\author{
Luma da Silva MIRANDA (D) \\ Universidade Eötvös Loránd (ELTE)
}

\section{RESUMO}

Esta resenha apresenta resultados de três trabalhos sobre instrução e treinamento fonético no ensino de pronúncia de segunda língua (L2). Atualmente, o treinamento fonético está voltado para a melhoria da inteligibilidade da fala do aprendiz de L2. As pesquisas foram aplicadas com falantes de diferentes línguas que eram aprendizes de inglês ou de mandarim como L2. Os resultados de uma série de experimentos com pré e pós-treinamento apontam para a eficácia da instrução e do treinamento fonético no ensino de pronúncia de L2. O principal objetivo desse tipo de prática é não só fazer os aprendizes adquirirem consciência fonológica na línguaalvo, mas também facilitar seu processo de aprendizagem na L2.

OPEN ACCESS

EDITADO POR

Raquel Freitag

AVALIADO POR Ubiratã Kickhofel Alves

DATAS

Recebido: 18/05/2020

Aceito: 25/05/2020 Publicado: 10/07/2020

COMO CITAR

Miranda, L. S. (2020). A contribuição da instrução e do treinamento fonético no ensino de L2. Revista da Abralin, v. 19, n.

2, p. 1-5, 2020.

\section{ABSTRACT}

This review presents the results of three works on instruction and training in second language (L2) pronunciation teaching. Currently, the phonetic training is aimed at improving the L2 learner's speech intelligibility. The researches were applied to speakers of different languages who were learners of either English or Mandarin as L2. The results of a series of pre-and posttraining experiments indicate the efficacy of instruction and training in the L2 pronunciation teaching. The main goal of this type of practice is not only to make learners achieve phonological awareness in the target language, but also to facilitate their L2 learning process. 


\section{REVISTA DA ABRALIN}

PALAVRAS-CHAVE

Fonética. Treinamento. L2.

KEYWORDS

Phonetics. Training. L2.

Na mesa-redonda intitulada "Fonética e Fonologia de L2: Instrução e Treinamento", moderada pelo professor Ubiratã Alves da Universidade Federal do Rio Grande do Sul, Brasil, foram apresentados trabalhos que mostram como pesquisas experimentais feitas com instrução e treinamento fonético estão a serviço do ensino de pronúncia de língua estrangeira e de segunda língua (doravante, L2).

Atualmente, o ensino de pronúncia de L2 é tratado como uma importante etapa do desenvolvimento das habilidades comunicativas do aprendiz e não mais como um treinamento mecânico de cunho behaviorista que tem um fim em si mesmo (CELCE-MURCIA et al., 2010; ALVES, 2015; KUPSKE; ALVES, 2017; LEVIS, 2018). Isso significa que há uma proposta integrada do ensino de pronúncia que reúne o treinamento fonético dos sons da L2, ou seja, um foco em aspectos formais da língua, e o objetivo comunicativo maior do ensino de pronúncia, que é melhorar a inteligibilidade da comunicação do aprendiz na L2.

Três professores participaram desta mesa-redonda, apresentando os resultados de suas pesquisas. O primeiro trabalho apresentado foi o da professora Anabela Rato da University of Toronto, Canadá. O segundo foi o do professor Pedro Luchini da Universidad Nacional de Mar del Plata, Argentina. O terceiro foi o da professora Xinchun Wang da California State University, Estados Unidos.

Na apresentação do primeiro trabalho, cujo título é "Avaliação da eficácia do treinamento fonético: retenção da aprendizagem", a professora Anabela Rato enfocou a capacidade do aprendiz de L2 (falantes portugueses que estão aprendendo inglês) de reter a informação adquirida no treinamento fonético na memória de longo prazo, para que essa informação possa ser aplicada em um momento posterior ao do treinamento.

O método de verificação dos efeitos do treinamento fonético perceptivo se caracteriza, basicamente, por quatro etapas, como na sequência de testes usada no estudo de Rato (2013): pré-teste, treinamento fonético, pós-teste e pós-teste tardio. Anabela Rato declarou que muitos estudos na literatura (RATO, 2013; SAKAI, 2016; ALIAGA-GARCIA, 2017; CARLET, 2017; SAKAI; MOORMAN, 2017) sugerem que os efeitos do treinamento fonético de produção são verificados na percepção, mas o contrário nem sempre se verifica.

Os resultados do estudo de Anabela Rato (2013) mostraram que há um efeito positivo a longo prazo na produção e na percepção dos aprendizes portugueses em relação às vogais do inglês $(/ \mathrm{i} /-/ \mathrm{I} /, / \varepsilon /-$ $/ æ /, / v /-/ u /)$, após a aplicação do treinamento fonético perceptivo. Rato ressaltou que a aprendizagem da pronúncia dos sons da L2 pode ainda ocorrer mesmo depois do término do treinamento fonético. 


\section{REVISTA DA ABRALIN}

Na segunda apresentação, "Enseñanza explícita y incidencia de rasgos prosódicos en el desarrollo de una pronunciación en L2 cercana a la de hablantes nativos de inglés", o professor Pedro Luchini reportou os resultados de sua pesquisa sobre o ensino explícito de aspectos prosódicos (LUCHINI, 2014), como a localização do acento tonal, o ritmo, a entoação, a velocidade de fala, entre outros, com foco na entoação, no desenvolvimento da pronúncia de aprendizes hispanofalantes de inglês como L2.

O objetivo do trabalho de Luchini era medir o grau de aproximação entre a produção desses traços prosódicos dos aprendizes de inglês como segunda língua e a dos falantes nativos de inglês. O autor fez uso de uma sequência didática elaborada para promover a conscientização linguística dos alunos.

Em seu estudo experimental, o professor Luchini reuniu dois grupos de aprendizes de inglês como L2, em que um deles receberia um treinamento fonético sem componente comunicativo, isto é, apenas com tarefas de treinamento, como repetição e ditado. Outro grupo, além do treinamento fonético tradicional, também recebeu tarefas com componente comunicativo. Essas tarefas comunicativas foram trabalhadas exclusivamente em uma parte da aula de maneira progressiva e com foco na prosódia.

Após a aplicação dos treinamentos fonéticos com os dois grupos, verificaram-se dois tipos de resultados. Enquanto no grupo A, houve uma melhora no domínio do ritmo, da velocidade de fala, da compreensibilidade e da fluidez, no grupo B, as tarefas comunicativas trouxeram vantagens significativas no domínio de traços prosódicos que favorecem uma produção mais próxima da produção do falante nativo do inglês, como a localização do acento tonal, quantidade e duração de pausas, bem como a diminuição do sotaque estrangeiro.

O estudo de Luchini mostrou que o ensino explícito da prosódia da L2 traz vantagens. Em relação aos resultados do estudo, o professor concluiu que, se o objetivo do ensino é obter melhorias a curto prazo, o tratamento aplicado ao grupo A é recomendado. Por outro lado, se o objetivo do ensino for obter melhorias a longo prazo, recomenda-se o tratamento dado ao grupo B. O professor também realçou que a inclusão de tarefas com estratégias metacognitivas, como a autorreflexão, a autoavaliação e o automonitoramento, nas aulas de pronúncia de L2 traz benefícios.

No último trabalho da mesa-redonda, intitulado "L2 speech learning: perception, production and training", a professora Xinchun Wang apresentou os resultados de estudos de produção e de percepção de consoantes do mandarim com falantes de língua inglesa aprendizes de mandarim, treinamento fonético de consoantes e tons do mandarim no nível da sílaba e da sentença, bem como treinamento fonético das vogais do inglês com aprendizes chineses.

Wang mostrou que seus estudos de treinamento fonético com vogais foram mais bem-sucedidos de que os estudos com treinamento de consoantes. Por um lado, comparando os resultados dos estudos das consoantes do mandarim como L2, em relação à percepção de dez consoantes $(/$ ts $/$, $\left./ \mathrm{ts}^{\mathrm{h}} /, / \mathrm{s} /, / \mathrm{t} \mathrm{c} /, / \mathrm{t}^{\mathrm{h}} /, / \mathrm{c} /, / \mathrm{ts} /, / \mathrm{ts}^{\mathrm{h}} /, / \mathrm{s} /, / \mathrm{z} /\right)$ e à produção de oito consoantes $\left(/ \mathrm{ts} /, / \mathrm{ts}^{\mathrm{h}} /\right.$, $\left./ \mathrm{s} /, / \mathrm{t} 6 /, / \mathrm{t}^{\mathrm{h}} /, / \mathrm{c} /, / \mathrm{ts} /, / \mathrm{ts}^{\mathrm{h}} /\right)$, verificou-se uma correlação na percepção e na produção dos aprendizes apenas de dois fonemas $\left(/ \mathrm{t}^{\mathrm{h}} /, / \mathrm{ts}^{\mathrm{h}} /\right)$, o que mostra que há um gap entre a produção e a percepção. Por outro lado, no estudo de treinamento fonético com três pares de vogais do inglês (heed/hid, who'd/hood, head/had), que foi aplicado com falantes de mandarim e cantonês, 


\section{REVISTA DA ABRALIN}

aprendizes de inglês como L2, verificou-se um efeito positivo para a percepção dessas vogais (e o aprendizado foi retido), mas não na produção.

Além disso, enquanto o treinamento fonético dos tons no nível da sílaba obteve melhora na produção e na percepção dos aprendizes de mandarim como L2, o treinamento dos tons no nível da sentença foi efetivo apenas para uma melhor produção dos aprendizes, mas não para a percepção.

Segundo as apresentações e a discussão final desta mesa-redonda, pode-se afirmar que as pesquisas sobre treinamento fonético, seja no nível segmental, seja no nível suprassegmental, estão a serviço, em primeiro lugar, da conscientização fonológica dos aprendizes de uma L2 e, eventualmente, da melhoria da inteligibilidade da pronúncia desses aprendizes (MUNRO; DERWING, 1995; DERWING; MUNRO, 2015; LEVIS, 2005; 2018). O professor de língua estrangeira, ao notar que seus alunos têm dificuldade de produzir ou perceber sons da L2, deve abordar esses aspectos formais em suas aulas, com o objetivo de melhorar a aprendizagem dos alunos.

Os três trabalhos apresentaram pesquisas de alta qualidade com um referencial teórico sólido, métodos e resultados claros, bem como sugestões promissoras de investigações futuras baseadas nos resultados positivos das análises. A principal mensagem da mesa-redonda é que não se deve ensinar pronúncia com o objetivo de alcançar o padrão nativo da L2 em questão e sim com foco na inteligibilidade da fala do aprendiz de L2. Os trabalhos apresentados na mesa, portanto, confirmam que as práticas de instrução e treinamento podem contribuir para tal fim.

\section{REFERÊNCIAS}

ALIAGA-GARCIA, Cristina. The effect of auditory and articulatory phonetic training on the perception and production of L2 vowels by Catalan-Spanish learners of English. PhD thesis. Universitat Autonoma de Barcelona, Barcelona, Espanha, 2017. Disponível em: https://www.tdx.cat/handle/10803/471451\#page=1. Acesso em: 26 maio 2020

ALVES, Ubiratã Kickhöfel. Ensino de pronúncia na sala de aula de língua estrangeira: questões de discussão a partir de uma concepção de língua como sistema adaptativo e complexo. Versalete, Curitiba, v. 3, n. 5, p. 374-396, 2015 .

CARLET, Angélica Foresti. L2 perception and production of English consonants and vowels by Catalan speakers: The effects of attention and training task in a cross-training study. PhD thesis. Universitat Autonoma de Barcelona, 2017. Disponível em: http://www.tdx.cat/handle/10803/403758. Acesso em: 26 maio 2020.

CELCE-MURCIA, M.; BRINTON, D.; GOODWIN, Janet; GRINER, Barry. Teaching Pronunciation: a course book and reference guide. Cambridge: Cambridge University Press, 2010.

DERWING, T.; MUNRO, M. Pronunciation fundamentals: evidence-based perspectives for L2 teaching and research. Amsterdam: John Benjamins Publishing Company, 2015.

FONÉTICA e Fonologia de L2: Instrução e Treinamento. Mesa-redonda debatida por Ubiratã Alves, Anabela Rato, Pedro Luchini e Xinchun Wang [s.l., s.n], 2020. 1 vídeo (2h 33min 48s). Publicado pelo canal da Associação Brasileira de Linguística. Disponível em: https://www.youtube.com/watch?v=rrAWyqoIU2g. Acesso em: 15 maio 2020. 


\section{REVISTA DA ABRALIN}

KUPSKE, F. F.; ALVES, U. K. Orquestrando o caos: o ensino de pronúncia de língua estrangeira à luz do paradigma da complexidade. Fórum Linguístico, Florianópolis, v. 14, n. 4, p. 2771-2784, 2017.

LEVIS, John. Intelligibility, oral communication, and the teaching of pronunciation. Cambridge: Cambridge University Press, 2018.

LEVIS, John. Changing concepts and shifting paradigms in pronunciation teaching. TESOL Quarterly, Virginia, v. 39, n. 3, p. 369-377, 2005.

LUCHINI, Pedro Luis. Incidencia de rasgos prosódicos en la adquisición de una pronunciación cercana a la nativa en los alumnos de inglés: Un estudio comparativo con diseño experimental misto. Tese (Doutorado em Letras). Universidad Nacional de Mar del Plata, Mar del Plata, Argentina, 2014.

MUNRO, M.; DERWING, T. Foreign accent, comprehensibility and intelligibility in the speech of second language learners. Language Learning, Michigan, v. 45, p. 73-97, 1995.

RATO, Anabela Alves dos Santos. Cross-Language Perception and Production of English Vowels by Portuguese Learners: The Effects of Perceptual Training. Tese (Doutorado em Letras). Universidade do Minho, Braga, Portugal, 2013.

SAKAI, Mari. (Dis)Connecting perception and production: Training native speakers of Spanish on the English /i//I/ distinction. 2016. PhD dissertation. Georgetown University, Washington, EUA. Disponível em: https://repository.library.georgetown.edu/bitstream/handle/10822/1042879/Sakai_georgetown_0076D_1351 8.pdf?sequence=1\&isAllowed=y. Acesso em: 26 maio 2020.

SAKAI, M.; MOORMAN, C. Can perception training improve the production of second language phonemes? A meta-analytic review of 25 years of perception training research. Applied Psycholinguistics, Cambridge, v. 39/1, pp. 187-224, 2017. DOI: https://doi.org/10.1017/S0142716417000418 